\title{
BMJ Open Changes in public preferences for technologically enhanced surveillance following the COVID-19 pandemic: a discrete choice experiment
}

\author{
Chris Degeling (D) , ${ }^{1}$ Gang Chen, ${ }^{2}$ Gwendolyn L Gilbert (D) , ${ }^{3,4}$ Victoria Brookes, ${ }^{5}$ \\ Thi Thai, ${ }^{2}$ Andrew Wilson, ${ }^{6}$ Jane Johnson ${ }^{4,7}$
}

To cite: Degeling C, Chen G, Gilbert GL, et al. Changes in public preferences for technologically enhanced surveillance following the COVID-19 pandemic: a discrete choice experiment. BMJ Open 2020;10:e041592. doi:10.1136/ bmjopen-2020-041592

- Prepublication history and additional material for this paper is available online. To view these files, please visit the journal online (http://dx.doi.org/10. 1136/bmjopen-2020-041592).

Received 12 June 2020 Revised 18 0ctober 2020 Accepted 29 October 2020
Check for updates

(C) Author(s) (or their employer(s)) 2020. Re-use permitted under CC BY-NC. No commercial re-use. See rights and permissions. Published by BMJ.

For numbered affiliations see end of article.

Correspondence to

Dr Chris Degeling;

degeling@uow.edu.au and

Dr Gang Chen;

gang.chen@monash.edu

\section{ABSTRACT}

Objectives As governments attempt to navigate a path out of COVID-19 restrictions, robust evidence is essential to inform requirements for public acceptance of technologically enhanced communicable disease surveillance systems. We examined the value of core surveillance system attributes to the Australian public, before and during the early stages of the current pandemic.

Design A discrete choice experiment was conducted in Australia with a representative group of respondents, before and after the WHO declared COVID-19 a Public Health Emergency of International Concern. We identified and investigated the relative importance of seven attributes associated with technologically enhanced disease surveillance: respect for personal autonomy; privacy/confidentiality; data certainty/confidence; data security; infectious disease mortality prevention; infectious disease morbidity prevention; and attribution of (causal) responsibility. Specifically, we explored how the onset of the COVID-19 outbreak influenced participant responses. Setting and participants 2008 Australians (general public) completed the experiment: 793 before COVID-19 outbreak onset (mean age 45.9 years, $50.2 \%$ male) and 1215 after onset (mean age 47.2 years, $49 \%$ male). Results All seven attributes significantly influenced respondents' preferences for communicable disease surveillance systems. After onset, participants demonstrated greater preference for a surveillance system that could prevent a higher number of illnesses and deaths, and were less concerned about their personal autonomy. However, they also increased their preference for a system with high data security.

Conclusions Public acceptance of technology-based communicable disease surveillance is situation dependent. During an epidemic, there is likely to be greater tolerance of technologically enhanced disease surveillance systems that result in restrictions on personal activity if such systems can prevent high morbidity and mortality. However, this acceptance of lower personal autonomy comes with an increased requirement to ensure data security. These findings merit further research as the pandemic unfolds and strategies are put in place that enable individuals and societies to live with SARS-CoV-2 endemicity.
Strengths and limitations of this study

- Our cross-sectional survey using discrete choice experiments (DCEs) empirically informs decisionmaking about the use of technologically enhanced surveillance systems.

- DCE uses scenarios so that respondents can demonstrate their preference trade-offs between surveillance system attributes, enabling identification of the attributes that most influence system acceptability, as well as the expected level of heterogeneity of preferences for these systems.

- The use of a cross-sectional survey in this study before and after pandemic onset enabled investigation of the situation-dependent nature of preferences about technologically based surveillance systems.

- Further, it provides unique insight into how such attitudes change in light of a significant and evolving disease threat and shifting policy context.

- A limitation of the current study is that internet access was required for participation.

\section{INTRODUCTION}

COVID-19 has swept across the globe, challenging public health and clinical capacities in many countries. ${ }^{1}$ While rapid case identification, contact tracing and quarantine are vital tools to control the spread of the virus, new technology and novel sources of health information have the potential to significantly enhance communicable disease surveillance systems, delivering earlier detection, more accurate tracking and better disease containment. ${ }^{23}$ Experiences in South Korea, Taiwan and Singapore indicate that more timely and accurate identification of cases and contacts could reduce the adverse health, social and economic impacts associated with infectious disease threats such as COVID-19. ${ }^{45}$ However, others have argued that these technologies are unproven and may present significant risks to personal privacy and may be open to misuse. ${ }^{6-8}$ 
Emerging infectious disease threats are by their nature unexpected, with unpredictable impacts. They cause fear (for life, health, security and/or reputation) among the public and other stakeholders. In most jurisdictions, state-run communicable disease surveillance activities are mandated by public health legislation with no opportunity to 'opt out', because of the significant public benefit of full participation. ${ }^{9}{ }^{10}$ As the impacts of COVID-19 grow, reports are highlighting differing levels of public support for and social cooperation with current public health measures in countries with different political traditions such as China, ${ }^{11}$ Italy $^{12}$ and the USA. ${ }^{13}$ However, when there is no immediate disease threat, in a liberal democracy such as Australia, the routine collection and linkage of detailed personal information could be regarded as intrusive and a threat to civil liberties, no matter how great the public health benefits. ${ }^{914}$

These concerns are not unreasonable. ${ }^{815}$ Digital epidemiologic investigations can reveal sources, transmission routes and personal information normally regarded as private; for example, where people have been, with whom and, potentially, the type of contact or activity involved. ${ }^{14} 16$ This is not necessarily resolved by making participation in communicable disease surveillance activities voluntary, because a significant proportion of the public might not opt in, which would markedly diminish the system's effectiveness. Conversely, there are also ethical and medicolegal risks and impacts from not using available information that could protect local and, potentially, international communities from serious disease outbreaks. ${ }^{17}$

To maximise the benefits of new technologies in liberaldemocratic jurisdictions, we need to understand and develop responses to public perceptions and concerns about technologically enhanced disease surveillance systems. If the use of new technology and new types of data to collect and integrate data for enhanced communicable disease surveillance is to be publicly acceptable and effective, it must gain a social licence to operate by aligning with community values and addressing ethical and legal barriers for use in research and public health action. ${ }^{14} 18$

Several factors influence social licence for novel uses of personal and health data, ${ }^{19}$ including for surveillance. ${ }^{20}$ The impact of these factors is unlikely to be homogenous, and may be conditional on individuals' circumstances and contexts. In Australia, previous research has focused on the perspectives of public health practitioners and policymakers, ${ }^{21-23}$ and, recently, informed citizens. ${ }^{24}$ While these research designs allow exploration of trade-offs among some attributes, there is a paucity of quantitative evidence for evaluation of the relative impacts of influential factors on the public acceptability and perceived legitimacy of different communicable disease surveillance systems.

Discrete choice experiments (DCEs) are a valid, reliable and widely applied survey methodology for eliciting community preferences for healthcare. ${ }^{25}$ They are superior to traditional attitudinal, satisfaction and ranking studies because they enable measurement of the strength of preferences for key aspects of a decision and, potentially, to quantify the trade-offs made between those factors in a way that is not possible with a simple ranking of preferences. ${ }^{21}{ }^{26}$ DCEs are particularly useful to understand public preferences for new technologies when revealed preference data are not yet available. This study aimed to elicit the preferences and choice trends for attributes associated with a technologically enhanced communicable disease surveillance. Data collection took place over two distinct periods before and after the global emergence of the COVID-19 pandemic; therefore, we sought to investigate and understand whether and how respondents' preferences were influenced by a public health crisis.

\section{METHODS}

DCE attributes and levels were determined based on consultations within the research team, discussions across our extended expert networks (including through presentations at Centre of Research Excellence in Emerging Infectious Diseases Colloquia in 2018 and 2019) and our team's Delphi study of Australian policymakers, health practitioners and lawyers. ${ }^{23}$ The final attributes and levels are presented in table 1.

The seven attributes and their corresponding levels resulted in 648 profiles (three attributes at two levels and four attributes at three levels), and a total of 209628 possible pairwise choices. An efficient design was used to generate a more manageable number of choice scenarios. Initially, a D-efficient design (with zero priors) was used to generate 48 choice scenarios (further blocked into four versions) for use in the pilot survey. The first task was a dominant choice test (one of the two alternatives should be chosen if a respondent makes a rational choice); only participants who passed this test had their responses analysed using a conditional logit model (110 out of 149 respondents who consented to the study). The estimated mean coefficients from this pilot were used as priors to recreate 96 choice scenarios using an efficient design. They were blocked into eight versions so that in the main study each respondent completed 12 valid choice scenarios and one dominant choice task. The DCE design was created in Ngene software V.1.2 (2018 ChoiceMetrics).

Two-stage choice scenarios were used to maximise the richness of data obtained from respondents (example in figure 1). The first stage involved a forced choice between two surveillance programmes. These data enabled an understanding of what members of the public value to prevent and control communicable disease outbreaks. Such data are particularly relevant if a compulsory surveillance system were to be established, and is the focus of this paper. The second-stage choice allowed respondents to 'opt-out' by indicating whether they would participate in the surveillance programme they preferred. This is 
Table 1 Attributes and levels

\begin{tabular}{lll} 
Attributes & Levels & \\
$\begin{array}{l}\text { Restriction of personal autonomy } \\
\text { Public health authorities can restrict } \\
\text { your freedom (involuntary quarantine or } \\
\text { immunisation) to prevent disease spread. }\end{array}$ & Yes & No \\
$\begin{array}{l}\text { Privacy/confidentiality } \\
\text { Access to your personal information. }\end{array}$ & $\begin{array}{l}\text { Controlled by you via } \\
\text { consent }\end{array}$ & $\begin{array}{l}\text { Can be gained by health } \\
\text { authorities without your } \\
\text { consent }\end{array}$ \\
$\begin{array}{l}\text { Data certainty/confidence } \\
\text { The quality of data collected is... }\end{array}$ & Low & High \\
$\begin{array}{l}\text { Data security } \\
\text { The protection of digital data is... }\end{array}$ & Poor & Moderate \\
$\begin{array}{l}\text { Infectious disease mortality prevention } \\
\text { Of } 1000 \text { potential deaths/year due to } \\
\text { infectious disease, this surveillance... }\end{array}$ & & High \\
\hline
\end{tabular}

\section{Infectious disease morbidity}

Prevents 10000 sick people Prevents 100000 sick people Prevents 1 million sick people prevention

Of the people who would otherwise get

sick and take time off work each year this surveillance...

$\begin{array}{llll}\text { Attribution of responsibility } & \text { All made public } & \begin{array}{l}\text { Kept confidential UNLESS a } \\ \text { risk remains for the public }\end{array} & \text { information is made public } \\ \text { Outcomes of infectious disease } & & \end{array}$

Please compare the programmes below and decide which one you would prefer.

We are interested in your opinion; there are no right or wrong answers.

\begin{tabular}{|c|c|c|}
\hline Please select one & Surveillance program $A$ & Surveillance program B \\
\hline \multicolumn{3}{|l|}{ Restriction of personal autonomy } \\
\hline $\begin{array}{l}\text { Public health authorities can restrict your freedom (involuntary quarantine } \\
\text { or immunisation) to prevent disease spread }\end{array}$ & No & Yes \\
\hline \multicolumn{3}{|l|}{ Privacy/confidentiality } \\
\hline Access to your personal information & $\begin{array}{l}\text { Can be gained by health authorities } \\
\text { without your consent }\end{array}$ & Controlled by you via consent \\
\hline \multicolumn{3}{|l|}{ Data certainty/confidence } \\
\hline The quality of data collected is ... & Low & High \\
\hline \multicolumn{3}{|l|}{ Data security } \\
\hline The protection of digital data is ... & High & Low \\
\hline \multicolumn{3}{|l|}{ Infectious disease mortality and prevention } \\
\hline Of 1,000 potential death/year due to infectious disease, this surveillance $\ldots$ & Prevents 100 deaths & Prevents 800 deaths \\
\hline \multicolumn{3}{|l|}{ Infectious disease morbidity prevention } \\
\hline $\begin{array}{l}\text { Of the people who would otherwise get sick and take time off work each } \\
\text { year this surveillance ... }\end{array}$ & Prevents 1 million sick people & Prevents 100,000 sick people \\
\hline \multicolumn{3}{|l|}{ Attribution of responsibility } \\
\hline Outcomes of infectious disease investigations are ... & $\begin{array}{c}\text { Kept confidential, no information is made } \\
\text { public }\end{array}$ & All made public \\
\hline
\end{tabular}

Would you participate in the surveillance program that you have preferenced above?

Yes

No

Figure 1: Sample DCE Task

Figure 1 Sample discrete choice experiment (DCE) task. 
informative for policymakers if programme participation were voluntary. This study focused only on the forcedchoice responses.

An online survey was conducted with a sample of the Australian public aged 18 years and older. An accurate calculation of sample size is difficult for DCEs, because actual preferences are unknown a priori. It is commonly suggested that to estimate reliable models, 20 respondents are sufficient per version of a DCE. ${ }^{26}$ For this DCE, considering the DCE design (with eight versions) and the estimations from pilot data, a target of $n=2000$ was considered sufficient to meet the requirements for the precise estimation of model parameters as well as allowing for subsample analyses and the exploration of preference heterogeneity. The sample size was substantially larger than previous DCEs conducted in similar contexts; for example, Russo et $a l^{21} \quad(\mathrm{n}=122)$. The respondents were recruited by an online panel recruitment company (Dynata; www.dynata.com). Respondents provided informed consent before accessing the survey and could withdraw at any time.

The study was conducted between 25 November 2019 and 27 February 2020. To ensure the survey was running as intended, we reviewed the data approximately halfway through recruitment. Thus data collection ceased temporarily on 10 January 2020 and resumed on 4 February. During this time, Australian attention had begun to focus on COVID-19 as the first Australian case was confirmed by the Australian Government on 25 January 2020 and the WHO declared COVID-19 a Public Health Emergency of International Concern on 30 January 2020 (figure 2). Under this natural experiment, respondents in the second period of data collection began to be exposed to the introduction of public health and security measures (advice to reconsider need to travel internationally; borders closed

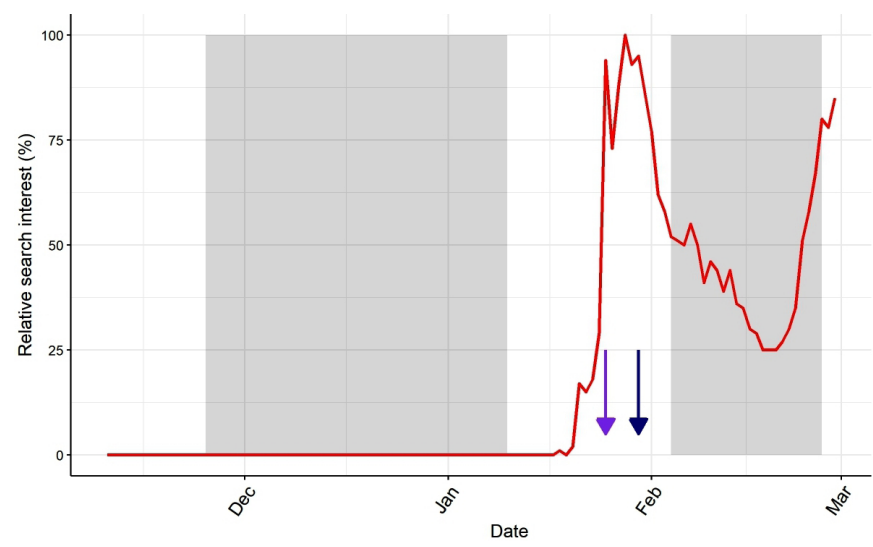

Figure 2 Plot showing the two periods of data collection (grey boxes: 25 November 2019 to 10 January 2020 and 4 February 2020 to 27 February 2020), relative internet search interest in 'coronavirus' in Australia reported by Google Trends (red line; https://trends.google.com), the timing of the first case reported in Australia (purple arrow: 25 January 2020) and WHO declares COVID-19 outbreak a Public Health Emergency of International Concern (blue arrow: 30 January 2020). to Chinese and Iranian nationals; enhanced passenger screening at points of entry).

The DCE data were analysed using the random utility theory framework. ${ }^{26}$ A conditional logit model was initially used to investigate respondents' preferences for the use of a technologically enhanced communicable disease surveillance, assuming a homogeneous preference among respondents. This latter assumption was subsequently relaxed to allow for potential preference heterogeneity among respondents using a mixed logit model. ${ }^{27}$ Effect coding was used for all attributes in the main regression analyses. The Bayesian information criterion (BIC) was used to facilitate the selection of optimal estimation between conditional logit and mixed logit models (the smaller value of BIC, the better the model fit). We investigated the DCE data before and after COVID-19 outbreak onset. The relative importance of each attribute was calculated by dividing the utility range of a particular attribute by the sum of utility ranges for all attributes. In the online supplemental material we also present an alternative modelling strategy in which we examined to what extent the COVID-19 shock influenced respondents' preferences by including interaction terms between a time dummy and attribute levels in the regression analysis (statistically significant interaction terms highlight the influence of COVID-19 exposure to respondents' preferences). All statistical analyses were conducted in Stata 15 (2017 StataCorp).

\section{Patient and public involvement}

Members of the public were invited to comment on the study design during piloting of the content and wording of the attributes and levels used to construct the scenarios but were not consulted to interpret the results. Members of the public were not invited to contribute to the writing or editing of this document for readability or accuracy.

\section{FINDINGS}

A total of 2008 respondents who passed the rationality test (the dominant choice task) were included in the main analysis (table 2). The median time for completion of the survey was $9.9 \mathrm{~min}$. Respondents had a median age of 46 (range 18-89) years and 51\% were female. Approximately one-third of respondents did not live in a metropolitan area (38\%), had completed a bachelor's or graduate degree $(38 \%)$, worked as a full-time employee $(35 \%)$ or had a weekly income of $>\$$ A1250 $(35 \%)$. The vast majority of respondents $(86 \%)$ rated the survey as 'Easy' or 'Very Easy'. The two subsamples who completed the survey before and after the onset of the COVID-19 outbreak were comparable across all the characteristics described above (all $\mathrm{p}>0.1$ ).

The DCE results based on the mixed logit model are discussed here because these models were better fitting than the conditional logit model. The detailed full sample estimations based on all 2008 respondents for all models are presented in the online supplemental table 1. 
Table 2 Respondent characteristics

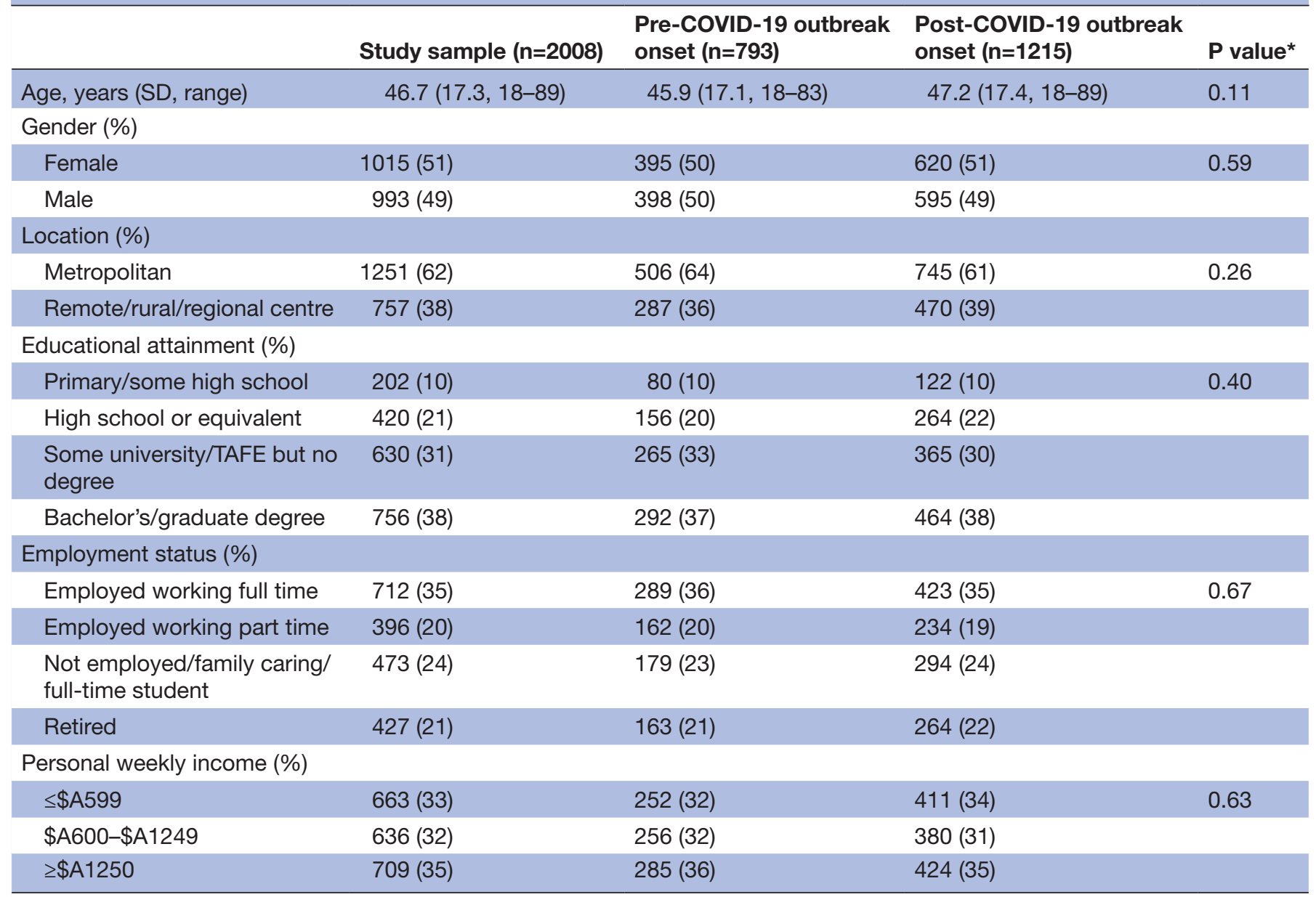

Data are $\mathrm{n}(\%)$ or mean (SD), unless otherwise indicated.

In the most recent Australian census, the proportions of female and non-metropolitan respondents were $51 \%$ and $29 \%$, respectively, the median age and weekly personal income were 38 years and \$A662, respectively, and 22\% of Australians had a bachelor's degree or higher qualification (https://quickstats.censusdata.abs.gov.au/census_services/getproduct/census/2016/quickstat/036).

${ }^{*} P$ values indicate the differences in respondent characteristics between two subsamples before versus after COVID-19 outbreak onset.

TAFE, Technical and Further Education.

Differences between the overall relative importance of attribute levels were apparent before and after COVID-19 outbreak onset, and are illustrated by the range of point estimates for each attribute in figure 3 , and quantified in table 3. All attributes were statistically significant indicating that each was important to respondents when selecting a communicable disease surveillance programme (online supplemental table 2). 'Infectious disease mortality prevention' and 'infectious disease morbidity prevention' ranked as the attributes with the greatest importance to respondents during both collection periods, and both were of increased importance after the onset of COVID19. 'Privacy', 'data certainty', 'data security' and 'attribution' were of relatively less importance. 'Restriction of personal autonomy' was the least important attribute, and it was notable that after the onset of COVID-19, the relative importance of 'data security' rose while the attribute 'restriction of personal autonomy' became even less important.
Figure 3 also illustrates variation in the point estimates for each attribute's levels, before and after COVID-19 onset. The significant SDs of at least one level within each attribute demonstrate the existence of preference heterogeneity (online supplemental table 2). However, during both periods, respondents on average valued their personal autonomy and their privacy, preferring a system that would not result in restrictions, as well as maintaining control over access to and dissemination of personal information such as their identity, location and health history. Respondents preferred a communicable disease surveillance programme to have high data certainty/confidence to detect disease when present (ie, surveillance strategies that have a diagnostic sensitivity of $>90 \%$ ) and to have high data security to prevent unauthorised or harmful use. They also valued a system that was able to detect, track and contain infectious disease threats to prevent more deaths or to prevent more illness. Regarding the attribution of causal responsibility for an 


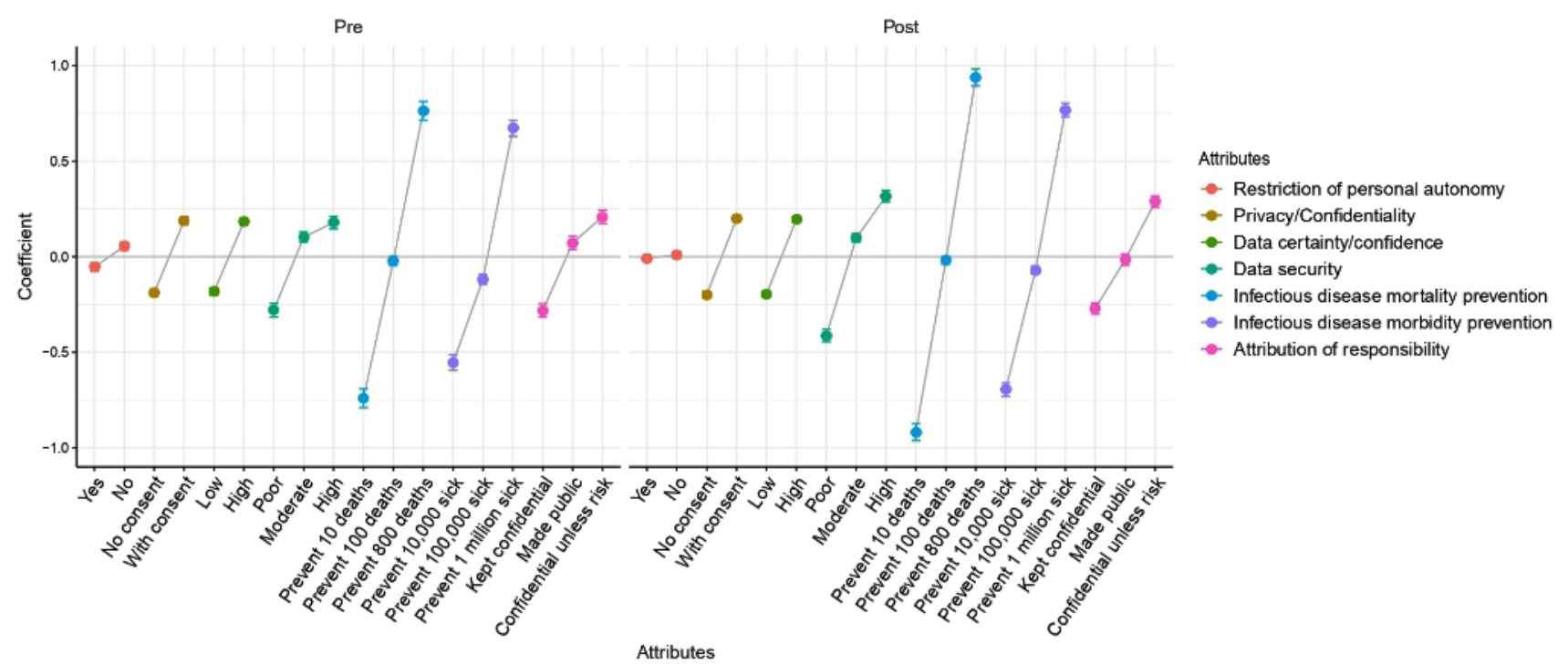

Figure 3 A comparison on preference before versus after COVID-19 onset (constructed based on regression coefficients reported in online supplemental document).

outbreak, respondents mostly preferred to keep this information confidential unless there was an imminent risk associated with non-disclosure, followed by the option of keeping all information confidential independent of the level of risk to the public. Making all outcomes of infectious disease investigations available to the public was viewed negatively.

The first difference to be noted in the importance of levels of attributes before and after COVID-19 outbreak onset is in the 'restriction of personal autonomy' attribute, which shows that respondents significantly preferred that public health authorities not restrict an individual's freedom (eg, compulsory quarantine or immunisation) to prevent disease spread before COVID-19 onset; however, this attribute becomes insignificant in the postonset period (figure 3; online supplemental table 2). Another difference is that during the preonset period, respondents

Table 3 The relative importance of each attribute, \%

Post-

Pre-COVID-19 COVID-19

\begin{tabular}{llc}
\hline $\begin{array}{l}\text { Restriction of personal } \\
\text { autonomy }\end{array}$ & 2.4 & 0.3 \\
\hline $\begin{array}{l}\text { Privacy/confidentiality } \\
\text { Data certainty/confidence }\end{array}$ & 8.3 & 7.4 \\
\hline $\begin{array}{l}\text { Data security } \\
\begin{array}{l}\text { Infectious disease mortality } \\
\text { prevention }\end{array}\end{array}$ & 10.1 & 7.2 \\
$\begin{array}{l}\text { Infectious disease morbidity } \\
\text { prevention }\end{array}$ & 27.1 & 13.5 \\
\hline \begin{tabular}{l} 
Attribution of responsibility \\
\hline
\end{tabular} & 10.8 & 27.0 \\
\hline
\end{tabular}

The relative importance of each attribute represents how much difference each attribute could influence in the total utility function. They were calculated based on regression results presented in figure 3. were keen that the outcomes of communicable disease investigations should be kept confidential and no information be made public, while in the postonset period, this attribute level becomes insignificant. Thus, while prepandemic there was a preference for not restricting civil liberties to stop disease spread, after the pandemic had started, participants did not care about civil liberties compared with the other options in the choice set. These pre-post COVID-19 outbreak differences provided strong evidence on how the emerging public health crisis influenced general public preferences towards autonomy and privacy.

Results from an alternative modelling strategy in which a series of interaction terms between DCE attribute levels and a time dummy indicating the survey was conducted after COVID-19 outbreak onset were also investigated (online supplemental table 3 ). This shows that, in addition to what has been discussed above, respondents valued, significantly more highly, a surveillance programme that has high data security and can prevent more people from becoming ill and dying.

Using the regression coefficients in figure 3 , we can begin to assess the relative acceptability to the public of different surveillance programmes. Consider two hypothetical surveillance programmes, A and B, which both have high privacy, data quality and security, can prevent 800 deaths and 1 million sick people and the investigation results are kept confidential unless there is an imminent risk associated with non-disclosure; the only difference is that in programme A public health authorities can restrict the freedom of individuals while in programme B authorities cannot. The probability to prefer programme A versus programme B is estimated to be $47 \%$ vs $53 \%$ in the pre-COVID-19 period and $50 \%$ vs $50 \%$ in the post-COVID-19 onset period. As another example, two hypothetical surveillance programmes $\mathrm{A}$ and $\mathrm{B}$ both have identical reference levels in all attributes except 
for mortality prevention. If programme $\mathrm{A}$ is capable of preventing 10 deaths while programme $\mathrm{B}$ can prevent 800 deaths, the probability to choose programme A versus B is estimated to be $18 \%$ vs $82 \%$ in the pre-COVID- 19 period and $14 \%$ vs $86 \%$ in the post-COVID-19 onset period.

As a sensitivity analysis, online supplemental table 4 further shows that further including those who failed the rationality test in the DCE analysis, the conclusions are mostly comparable to what have been reported above.

\section{CONCLUSIONS}

Global experience and our findings highlight that many individuals are likely to accept limits on personal autonomy in pursuit of population health benefits at times when members of the public are being told to prepare for a major health emergency. This is consistent with the use of legislation to enforce social distancing and other infection control and prevention measures that have been implemented, to varying extents, worldwide in the current pandemic. At the time of the second phase of this survey, COVID-19 cases and mortality were growing in many countries, and the early data being publicly reported indicated rates of infection that were higher than the scenarios presented as part of our DCE. Moreover, people were experiencing or witnessing public health control measures with impacts on personal autonomy such as restrictions on travel, physical distancing measures, and school and workplace closures.

We have now entered a period in Australia and some other countries where case numbers have fallen and there is both public and economic pressure to ease restrictions and move to sustainable containment measures including apps for tracking potential COVID-19 contacts. As restrictions ease and attention is now turning to how best to live with SARS-CoV-2, many governments are asking their citizens to trade off some privacy to enable the return of more social freedoms through the uptake of more intrusive surveillance technologies. ${ }^{3} 62829$

In the Australian context, our study suggests that any acceptance of some loss of autonomy and privacy, after the onset of the COVID-19 pandemic, will be balanced against the increasing demand for data security. Notably, the trade-off between privacy, data security and 'usefulness' is a feature inherent to the design and application of most mobile phone health apps. ${ }^{30} 31$ Australian government agencies have a particularly poor record in managing citizens' health and administrative data. ${ }^{32}$ However, concerns about how surveillance data are secured and managed are likely to be generalisable to other liberal democracies, given worldwide data security breaches and the secondary use of data across many contexts. $^{33}$

The need for the outcomes of investigations to remain confidential, except if there is a risk to public safety, appears to also be part of the trade-off participants made in accepting the loss of liberal rights. Ensuring high data security, while providing transparency around how and when infection transmission is assigned, is likely to be an important factor in securing public trust and gaining social licence to operate technology-enhanced communicable disease surveillance. ${ }^{924}$ In Australia, as the COVID-19 outbreak has progressed, there have been increasing public demands for full transparency, in the face of varying case numbers and control measures in different jurisdictions, uncertainty about transmission routes, conflicting advice about personal risk and preventive measures, and suspicion that not enough (or too much) is being done. ${ }^{3435}$

Respondents' increased requirement to prevent higher levels of morbidity and mortality was expected, given the level of anxiety and uncertainty in the early stages of the current pandemic. The same requirement could have been expected for data quality of any surveillance system, considering the importance placed on it by Australian practitioners and policymakers, in expert and public discourses. ${ }^{23}{ }^{28}$ The decline in importance given to data certainty/confidence by respondents after COVID-19 outbreak onset suggests that its operational value might not have been widely appreciated at the time of data collection. In real-world systems, data accuracy, utility and privacy are competing attributes-such that a lack of data accuracy can either wrongly identify an individual as being affected, if data specificity is poor, or fail to detect another if sensitivity is lacking. In either case there is potential health risk, loss of trust in health authorities and inconvenience and/or loss of privacy to individuals or society.

Previous research has identified that public acceptability was a key consideration for Australian practitioners and policymakers, in deciding how and when to use technologies to enhance communicable disease surveillance systems. ${ }^{23}$ Unless the threat to public health was imminent, the potential for such systems to erode public trust was seen as a crucial barrier to implementation, whereby the development of publicly supported guidelines and systems of oversight was identified as a necessary condition for their operation. Therefore, the extent to which preferred surveillance system attributes remained stable between the two data collection periods is notable. Rather than a major reorientation of preferences and priorities after COVID-19 became a matter of global public health concern, participants' ranking of the attributes stayed the same-with only adjustments in the relative influence of each on the final decision (table 3). The uptake of contact tracing apps and future research will provide further insight into how much societies become encultured to higher levels of surveillance after the COVID-19 pandemic in order to sustain social and economic activities.

Finally, although online panels have been widely used in Australia and internationally for DCEs for health prioritisation, ${ }^{36}$ respondents need internet access to complete the online survey. Therefore, our respondents might represent a higher than average socioeconomic group (also reflected in their higher weekly income and education level). However, given that our focus in this survey is relative changes in perceptions rather than effect sizes of specific groups, we expect that our results are generalisable to the broader Australian population and are of relevance to countries with similar socioeconomic and political backgrounds. 


\section{Author affiliations}

${ }^{1}$ Australian Centre for Health Engagement, Evidence and Values, University of Wollongong, Wollongong, New South Wales, Australia

${ }^{2}$ Centre for Health Economics, Monash Business School, Monash University, Caufield East, Victoria, Australia

${ }^{3}$ Sydney Health Ethics, Sydney School of Public Health, The University of Sydney Faculty of Medicine and Health, Sydney, New South Wales, Australia

${ }^{4}$ Marie Bashir Institute for Emerging Infectious Disease and Biosecurity, The University of Sydney, Sydney, New South Wales, Australia

${ }^{5}$ School of Animal and Veterinary Sciences, Charles Sturt University, Wagga Wagga, New South Wales, Australia

${ }^{6}$ Menzies Centre for Health Policy, The University of Sydney, Sydney, New South Wales, Australia

${ }^{7}$ Department of Philosophy, Macquarie University, Sydney, New South Wales, Australia

\section{Twitter Gwendolyn L Gilbert @stopinfection}

Contributors This project was led by JJ, GC and CD, with input from GLG, VB and AW at the study design phase. GC, JJ and TT ran data collection and all authors participated in data analyses. VB and GC performed data visualisation. CD, GC and $\mathrm{JJ}$ drafted the manuscript. All authors contributed to manuscript revision and have seen and approved the final version.

Funding This research was funded by the Australian Government National Health and Medical Research Council (NHMRC) (project grant 1102962) and the Marie Bashir Institute for Infectious Disease and Biosecurity, The University of Sydney, Australia. The Centre of Research Excellence in Emerging Infectious Diseases (CREID) is funded by the Australian Government NHMRC (GNT1102962). GC is the recipient of an Australian Research Council Discovery Early Career Researcher Award (project number DE180100647) funded by the Australian Government.

Competing interests None declared.

Patient consent for publication Not required.

Ethics approval This study was approved by the Human Research Ethics Committee at The University of Sydney (project number: 2018/988).

Provenance and peer review Not commissioned; externally peer reviewed.

Data availability statement № data are available. No further data are available for sharing.

Supplemental material This content has been supplied by the author(s). It has not been vetted by BMJ Publishing Group Limited (BMJ) and may not have been peer-reviewed. Any opinions or recommendations discussed are solely those of the author(s) and are not endorsed by BMJ. BMJ disclaims all liability and responsibility arising from any reliance placed on the content. Where the content includes any translated material, BMJ does not warrant the accuracy and reliability of the translations (including but not limited to local regulations, clinical guidelines, terminology, drug names and drug dosages), and is not responsible for any error and/or omissions arising from translation and adaptation or otherwise.

Open access This is an open access article distributed in accordance with the Creative Commons Attribution Non Commercial (CC BY-NC 4.0) license, which permits others to distribute, remix, adapt, build upon this work non-commercially, and license their derivative works on different terms, provided the original work is properly cited, appropriate credit is given, any changes made indicated, and the use is non-commercial. See: http://creativecommons.org/licenses/by-nc/4.0/.

\section{ORCID iDs}

Chris Degeling http://orcid.org/0000-0003-4279-3443

Gwendolyn L Gilbert http://orcid.org/0000-0001-7490-6727

\section{REFERENCES}

1 World Health Organization. Coronavirus disease 2019 (COVID-19): situation report, 59. Geneva: WHO, 2020. https://apps. who.int/iris/ bitstream/handle/10665/331597/nCoVsitrep19Mar2020-eng.pdf

2 Legido-Quigley H, Asgari N, Teo YY, et al. Are high-performing health systems resilient against the COVID-19 epidemic? Lancet 2020;395:848-50.

3 Ferretti L, Wymant C, Kendall M, et al. Quantifying SARS-CoV-2 transmission suggests epidemic control with digital contact tracing. Science 2020;368:eabb6936.
4 Wang CJ, Ng CY, Brook RH. Response to COVID-19 in Taiwan: big data analytics, new technology, and proactive testing. JAMA 2020;323:1341-2.

5 Anderson RM, Heesterbeek $\mathrm{H}$, Klinkenberg D, et al. How will countrybased mitigation measures influence the course of the COVID-19 epidemic? Lancet 2020;395:931-4.

6 COVID-19 digital apps need due diligence. Nature 2020;580:563.

7 Ada Lovelace Institute. Exit through the APP store? a rapid evidence reveiw on the technical considerations and societal implications of using technology to transition from the COVID-19 crisis. United Kingdom, 2020.

8 Nay O. Can a virus undermine human rights? Lancet Public Health 2020:5:e238-9.

9 Fairchild AL, Haghdoost AA, Bayer R, et al. Ethics of public health surveillance: new guidelines. Lancet Public Health 2017;2:e348-9.

10 Klingler C, Silva DS, Schuermann C, et al. Ethical issues in public health surveillance: a systematic qualitative review. BMC Public Health 2017;17:295.

11 Pan X, Ojcius DM, Gao T, et al. Lessons learned from the 2019-nCoV epidemic on prevention of future infectious diseases. Microbes Infect 2020;22:86-91.

12 Horowitz J, Bubola E. On day 1 of Lockdown, Italian Officials urge citizens to Abide by rules. the new York times, 2020. Available: https://www.nytimes.com/2020/03/08/world/europe/italycoronavirus-quarantine.html [Accessed 19 Mar 2020].

13 Balz D, Guskin E. Poll finds universal lifestyle changes, rising stress and growing fears about catching coronavirus. The Washington Post, 2020. Available: https://www.washingtonpost.com/politics/pollfinds-universal-lifestyle-changes-rising-stress-and-growing-fearsabout-catching-coronavirus/2020/03/26/11360bb2-6f5e-11ea-b148e4ce3fbd85b5_story.html [Accessed 28 Mar 2020].

14 Gilbert GL, Degeling C, Johnson J. Communicable disease surveillance ethics in the age of big data and new technology. Asian Bioeth Rev 2019;11:173-87.

15 Stahl T. Indiscriminate mass surveillance and the public sphere. Ethics Inf Technol 2016;18:33-9.

16 Vayena E, Salathé M, Madoff LC, et al. Ethical challenges of big data in public health. PLoS Comput Biol 2015;11:e1003904.

17 Nuffield Council on Bioethics. Research in global health emergencies: ethical issues, 2020. www.nuffieldbioethics.org/publications/ research-in-global-health-emergencies

18 Aitken M, Tully MP, Porteous C, et al. Consensus statement on public involvement and engagement with data-intensive health research. Int J Popul Data Sci 2019;4.

19 Aitken M, de St Jorre J, Pagliari C, et al. Public responses to the sharing and linkage of health data for research purposes: a systematic review and thematic synthesis of qualitative studies. BMC Med Ethics 2016;17:73.

20 Smith GE, Elliot AJ, Lake I, et al. Syndromic surveillance: two decades experience of sustainable systems - its people not just data! Epidemiol Infect 2019;147:e101.

21 Russo PL, Chen G, Cheng AC, et al. Novel application of a discrete choice experiment to identify preferences for a national healthcareassociated infection surveillance programme: a cross-sectional study. BMJ Open 2016;6:e011397.

22 Rowe SL, Stephens N, Cowie BC, et al. Use of data linkage to improve communicable disease surveillance and control in Australia: existing practices, barriers and enablers. Aust N Z J Public Health 2019;43:33-40.

23 Degeling C, Johnson J, Gilbert GL. Perspectives of Australian policy-makers on the potential benefits and risks of technologically enhanced communicable disease surveillance - a modified Delphi survey. Health Res Policy Syst 2019;17:35.

24 Degeling C, Carter SM, van Oijen AM, et al. Community perspectives on the benefits and risks of technologically enhanced communicable disease surveillance systems: a report on four community juries. BMC Med Ethics 2020;21:31.

25 de Bekker-Grob EW, Ryan M, Gerard K. Discrete choice experiments in health economics: a review of the literature. Health Econ 2012;21:145-72.

26 Lancsar E, Louviere J. Conducting discrete choice experiments to inform healthcare decision making: a user's guide. Pharmacoeconomics 2008;26:661-77.

27 Hauber AB, González JM, Groothuis-Oudshoorn CGM, et al. Statistical methods for the analysis of discrete choice experiments: a report of the ISPOR conjoint analysis good research practices Task force. Value Health 2016;19:300-15.

28 Lewis P. Trust in the government is rising - but will Australians accept the coronavirus tracing app? The Guardian, Australia, 2020. Available: https://www.theguardian.com/australia-news/ 
commentisfree/2020/apr/20/trust-in-the-government-is-rising-butwill-australians-accept-the-coronavirus-tracing-app

29 Zastrow M. Coronavirus contact-tracing apps: can they slow the spread of COVID-19? Nature 2020:d41586-020-01514-2.

30 Huckvale K, Prieto JT, Tilney M, et al. Unaddressed privacy risks in accredited health and wellness apps: a cross-sectional systematic assessment. BMC Med 2015;13:214.

31 Dehling T, Gao F, Schneider S, et al. Exploring the far side of mobile health: information security and privacy of mobile health Apps on iOS and android. JMIR Mhealth Uhealth 2015;3:e8.

32 Daly A. The introduction of data breach notification legislation in Australia: a comparative view. Computer Law \& Security Review 2018;34:477-95.
33 Abouelmehdi K, Beni-Hssane A, Khaloufi H, et al. Big data security and privacy in healthcare: a review. Procedia Comput Sci 2017;113:73-80.

34 Blakely T. The public urgently needs more clarity on virus data. The Australian financial review, 2020. Available: https://www.afr.com/ policy/health-and-education/the-public-urgently-needs-more-clarityon-virus-data-20200330-p54f9o [Accessed 31 Mar 2020].

35 Shine J. Australia's leading scientists call for data underpinning COVID-19 decisions to be made public. Canberra: Australian Academy of Science, 2020.

36 Whitty JA, Ratcliffe J, Chen G, et al. Australian public preferences for the funding of new health technologies: a comparison of discrete choice and profile case best-worst scaling methods. Med Decis Making 2014;34:638-54. 